\title{
Airways changes related to air pollution exposure in wheezing children
}

\author{
P.C. Martins*,\#, J. Valente ${ }^{\ddagger}$, A.L. Papoila ${ }^{+}$, I. Caires*, J. Araújo-Martins ${ }^{\S}$, P. Mata ${ }^{f}$, \\ M. Lopes ", S. Torres**, J. Rosado-Pinto\#, C. Borrego", \\ I. Annesi-Maesano ${ }^{\# \#, \varphi^{\circ}}$ and N. Neuparth ${ }^{\star, \#}$
}

ABSTRACT: In this study, we aimed to evaluate the relationship between individual total exposure to air pollution and airway changes in a group of 51 wheezing children.

Respiratory status was assessed four times (January 2006, June 2006, January 2007 and June 2007) during a 1-week period through a standardised questionnaire, spirometry, exhaled nitric oxide fraction and $\mathrm{pH}$ in exhaled breath condensate (EBC). Concentrations of particles with a $50 \%$ cut-off aerodynamic diameter of $10 \mu \mathrm{m}(\mathrm{PM} 10), \mathrm{O}_{3}, \mathrm{NO}_{2}$ and volatile organic compounds were estimated through direct measurements with an ad hoc device or air pollution modelling in the children's schools and at their homes in the same 4 weeks of the study. For each child, total exposure to the different air pollutants was estimated as a function of pollutant concentrations and daily activity patterns.

Increasing total exposure to $\mathrm{PM}_{10}, \mathrm{NO}_{2}$, benzene, toluene and ethylbenzene was significantly associated with a decrease of forced expiratory volume in $1 \mathrm{~s}$ (FEV1) and with an increase of change in $\mathrm{FEV} 1$. Increasing exposure to $\mathrm{NO}_{2}$ and benzene was also related to a significant decrease of $\mathrm{FEV}_{1}$ /forced vital capacity. Increasing exposure to $\mathrm{PM}_{10}, \mathrm{NO}_{2}$, benzene and ethylbenzene was associated with acidity of EBC.

This study suggests an association in wheezing children between airway changes and total exposure to air pollutants, as estimated by taking into account the concentration in the various microenvironments attended by the children.

KEYWORDS: Breath condensate analysis, $\mathrm{NO}_{2}$, particles with a $50 \%$ cut-off aerodynamic diameter of $10 \mu \mathrm{m}$, spirometry, total exposure, volatile organic compounds

$\mathbf{V}$ arious cross-sectional [1-3] and longitudinal [4-7] studies have shown the effects of both indoor and outdoor air pollutants on the respiratory health of children. Most of these studies have focused on the relationship with symptoms or diseases, and few have investigated the links with lung function tests [8-10] and inflammatory markers $[8,9,11]$. However, evidence of changes over time in parameters related to air pollutant variations in the literature is scarce. In addition, assessment of exposure to air pollutants has not been exhaustive in most studies.

Background pollutant concentrations measured at central monitoring stations have usually been used $[12,13]$, followed up by traffic density/distance to major roads [13, 14] or dispersion models [3]. Only more recently was exposure to indoor environments, such as schools $[15,16]$ or houses where children spend $>80 \%$ of their time [17], also considered [18, 19]. Taken together, these studies have shown that there is a need for a more specific and precise assessment of exposure to maximise the potential information to be derived from epidemiological studies. Although continuous measurements of personal exposures for all study subjects for a complete study period might be considered the desired "gold standard" for exposure assessment, this is difficult to achieve due to feasibility constraints, as each participant has to carry special equipment $24 \mathrm{~h}$ per day for several days. To date, such studies $[20,21]$ have been scarce, focused on only some pollutants (e.g. particle matter [20]) and taken into account only part of the day.

An alternative strategy to achieve the assessment of total exposure to a pollutant could result from outdoor dispersion models [22], combined with direct objective measurements of air pollution in the different indoor environments attended by
AFFILIATIONS

${ }^{*}$ CEDOC, Departamento de

Fisiopatologia, Faculdade de

Ciências Médicas, Universidade

Nova de Lisboa,

${ }^{+}$Departamento de Bioestatística e Informática, Faculdade de Ciências Médicas, Universidade Nova de Lisboa, CEAUL,

\# Serviço de Imunoalergologia,

Hospital de Dona Estefânia, Centro Hospitalar de Lisboa Central, EPE,

${ }^{\S}$ Serviço 8 - Otorrinolaringologia,

Hospital de São José, Centro

Hospitalar de Lisboa Central, EPE, and

fInstituto Clínico de Alergologia, Lisbon,

"CESAM and Departamento de Ambiente e Ordenamento,

Universidade de Aveiro, Aveiro,

**Serviço de Pneumologia, Hospital

de São Teotónio, Viseu, Portugal.

\#\#INSERM, U707 EPAR, and

"Université Pierre et Marie Curie -

Paris Univ 06, UMR S 707 EPAR,

Paris, France.

CORRESPONDENCE

P.C. Martins

Departamento de Fisiopatologia

Faculdade de Ciências Médicas

Campo dos Mártires da Pátria

№. 130

1169-056 Lisbon

Portugal

E-mail: pmartinsalergo@gmail.com

Received:

Feb 092011

Accepted after revision:

June 052011

First published online:

June 302011 
children. In addition, repeated measures for the same individual can be introduced to overcome the reduced sample size issue. This is a common limitation of such studies that look for a more detailed approach to calculate exposure and aim to evaluate the respiratory status at the same time.

In this prospective study, we aimed to evaluate the relationship between total exposure to various air pollutants and airway changes in a group of wheezing children. The main peculiarities of this study were to estimate: 1) individual total exposure for each child for a wide range of air pollutants, taking into account different environments and the time spent by the child in these environments; 2) airway changes through spirometry and inflammatory biomarkers; and 3) repeated measures through consistently timed data methodology.

\section{MATERIAL AND METHODS \\ Population and protocol}

The Saud'Ar prospective panel study took place in Viseu, a nonindustrial city of Portugal with $\sim 50,000$ inhabitants, located $60 \mathrm{~km}$ from the coast in the northern central area of Portugal. After approval by the local ethics committee, the International Study of Asthma and Allergies in Childhood questionnaire was distributed to 806 children in four primary schools in order to identify those who had suffered from wheezing in the previous 12 months. The parents of children reporting wheezing symptoms were proposed, after signing the informed consent, to permit the children's participation in the study. The study consisted of four visits in January 2006, June 2006, January 2007 and June 2007. All of the participants were evaluated in the same week of the month at the Dept of Pneumology of São Teotónio Hospital, the main hospital in Viseu. With the agreement of the ethics committee, parents were invited to suspend asthma control medication (montelukast or inhaled corticosteroids) 3 weeks prior to evaluation if, and only if, the child's asthmatic status allowed such suspension. Stopping treatment was discussed with the doctor treating the child for asthma; however, children could take other medications.

In agreement with the ethics committee, parents were instructed to re-introduce asthma medication as soon as necessitated by the child's status, i.e. new symptoms, worsening of symptoms or attacks. Additionally, during the entire survey, a 24-h telephone line was available to the parents in order to answer to any questions on the child's health and an "open-door policy" was set up at the hospital outpatients' clinic for the study participants. Regular follow-up calls were also scheduled with the parents to question them on the health status of the child.

At the beginning of the study, only four children were receiving treatment (montelukast $n=2$, low-dose inhaled corticosteroids $n=2$ ). The remaining children used only rescue medication. No child needed immediate re-introduction of asthma medication during the survey.

At all visits, a short questionnaire concerning the presence of wheezing symptoms, use of rescue medication and emergency department visits in the previous 6 months was answered by parents. After returning the questionnaire, children performed the following clinical tests on the same day in the following order: exhaled breath condensate (EBC) collection for $\mathrm{pH}$ analysis, measurement of exhaled nitric oxide fraction ( $\mathrm{FeNO}$ ) and spirometry. Skin-prick tests to common inhalant allergens were performed during the first and last visit. More details about the methodology are presented in the online supplementary material.

Respiratory outcomes of interest were as follows. 1) Forced expiratory volume in $1 \mathrm{~s}$ (FEV1), FEV1/forced vital capacity (FVC) ratio, forced expiratory flow between $25-75 \%$ of FVC (FEF25-75\%) and improvement of FEV1 15 min after administration of $200 \mu \mathrm{g}$ of salbutamol $(\triangle \mathrm{FEV} 1)$. Lung function was expressed as the percentage of the predicted normal value. Spirometry was performed using a portable pneumotachograph (Vitalograph Compact; Vitalograph, Buckingham, UK). 2) FeNO in ppb and $\mathrm{pH}$ of $\mathrm{EBC}$ (after extraction of $\mathrm{CO}_{2}$ with argon) were the bronchial inflammatory outcomes. Measurement of FeNO was performed prior to spirometry using a portable analyser (Niox ${ }^{\circledR}$ Mino; Aerocrine, Solna, Sweden), in which the expiratory flow rate was maintained at $50 \mathrm{~mL} \cdot \mathrm{s}^{-1}$. An RTube (Respiratory Research Inc., Austin, TX, USA) was used for EBC collection. 3) Wheezing symptoms, use of rescue medication (bronchodilators such as salbutamol or terbutaline) and emergency department visits in the previous 6 months constituted the clinical outcomes.

\section{Air quality measurements}

Air quality assessment took place in the town of Viseu during the four previously mentioned periods. The measured outdoor parameters included ambient air concentrations of $\mathrm{O}_{3}, \mathrm{NO}, \mathrm{NO}_{2}$, CO and BTEX (benzene, toluene, ethylbenzene and xylenes), and particles with a $50 \%$ cut-off aerodynamic diameter of $10 \mu \mathrm{m}$ and $2.5 \mu \mathrm{m}$ (PM10 and PM2.5, respectively), which were measured continuously in three mobile laboratories: in the city centre, the school courtyard of the urban location and a suburban school courtyard. Additionally, at the urban school, both ambient PM10 and PM2.5 were measured by gravimetric methods (24-h mean) while for the suburban school only PM10 was measured, as only one set of equipment for PM2.5 was available. $\mathrm{O}_{3}$ and $\mathrm{NO}_{2}$ concentrations were also measured using diffusive samplers located at 20 points throughout the city of Viseu, in an area of $\sim 40 \mathrm{~km}^{2}$.

Volatile organic compound (VOC; such as formaldehyde and BTEX), $\mathrm{O}_{3}$ and $\mathrm{NO}_{2}$ measurements were performed in the four schools (courtyard and classrooms) and children's houses (bedrooms) using diffusive samplers. All parents of children included in the medical visits were asked to participate in the air quality studies.

Indoor PM10 and PM2.5 concentrations were measured at the urban school by gravimetric methods (24-h mean). In the suburban school, only PM10 was measured for the same reason as mentioned previously. Further details concerning air quality measurements are presented in online supplement.

\section{Air quality modelling}

The mesoscale modelling system MM5/CHIMERE (for full details see the online supplement) was applied to characterise the spatial distribution of air pollutants concentrations. More information concerning air quality modelling is presented in the online supplement.

\section{Exposure assessment estimation}

To estimate individual exposure to air pollutants, two main tasks were performed: 1 ) the estimation of the daily activity pattern of each child, which allowed the microenvironments frequented by 
children and the time spent in each one to be identified; and 2) the air quality characterisation of those microenvironments. The daily activity pattern was established through questionnaires administered to parents and children and a 5-day study week (Monday to Friday) was considered. The air quality evaluation in the identified microenvironments (outdoors and indoors) was performed using a multi-strategy approach: measurements during field campaigns and air quality modelling simulations to characterise areas where it was not possible to obtain measurements.

The individual exposure of each child to the different air pollutants was then estimated using a microenvironment approach and calculated (for a 5-day study week) according to the following equation:

$$
\operatorname{Exp}_{i}=\sum_{j=1}^{n} C_{j} t_{i, j}
$$

In this equation, $\operatorname{Exp}_{i}$ is the total exposure for the person $i$ over the specified period of time, $C_{j}$ is the pollutant concentration in microenvironment $j$, and $t_{i, j}$ is the time spent by the person $i$ in microenvironment $j$. Results are presented as the mean (minimum and maximum) of the means of exposure over a week. More details are presented in the online supplement.

\section{Statistical analysis}

Exploratory analysis of the variables of interest was performed. The Chi-squared test was used to compare proportions and Friedman's test was used to compare pollutants, weather conditions, and spirometric and inflammation outcomes during the four visits. A generalised estimating equation (GEE) approach with an exchangeable working correlation was used to estimate the association between exposure to each air pollutant and spirometric, inflammatory and clinical outcomes. Crude regression coefficients were calculated first. Given the potential for factors to confound or modify the associations between air pollution and respiratory health, we decided a priori to adjust all the models for age, sex, parental smoking, parental education, atopic status, time of the visit, average temperature and relative humidity on the day of the medical visit. Other variables drawn from the literature, such as height, weight, older siblings, mould or dampness at home, fireplace at home and presence of pets at home, were also included as they were associated with at least one health outcome in the univariable analyses $(p<0.15)$ and caused a change $(>10 \%)$ on at least one pollutant's estimated effect when included in the models. Factors such as body mass index, use of natural gas for cooking/heating and presence of air conditioning were excluded. For coherency, all the models were adjusted for the same confounders. This decision was taken as the studied outcomes share many common aspects. After stepwise analyses, variables were included all at once in the models. Spirometric variables (not adjusted for age, sex, height and weight) were expressed as percentage of predicted value. In order to take the significant correlations between the pairs of air pollutants into account, two-pollutant models including the concentrations of the two considered pollutants as independent variables were implemented. Crude and adjusted regression coefficients and corresponding 95\% confidence intervals were calculated for an increased exposure of $10 \mu \mathrm{g} \cdot \mathrm{m}^{-3} \cdot$ week $^{-1}$ of air pollutant.

Correlation matrix between the pollutants was computed at each visit using the Spearman's rank correlation.
The level of significance considered was $\alpha=0.05$, although $\mathrm{p}$ values $>0.05$ and $<0.1$ are still reported. Stata (StataCorp LP, TX, USA) for Windows was used to analyse the data.

\section{RESULTS}

Out of 806 distributed questionnaires, 645 (80\%) were completed by the parents. Among the children whose parents replied, $77(11.7 \%)$ reported wheezing in the previous 12 months, a frequency similar to the prevalence estimated in the paediatric Portuguese population. After contacting their parents, 54 children were allowed to participate. Herein, we present data from 51 children who reached the end of the study.

The description of the sample at the beginning of the study is presented in table 1 . The majority of children were males (55\%), with a mean \pm SD age at the end of the study of $8.8 \pm 1.1$ yrs. $27(53 \%)$ were atopic and all were Caucasian.

For each visit, baseline concentrations of VOCs for houses (indoors) and schools (indoors and outdoors) are presented in table 2. Indoor levels of $\mathrm{NO}_{2}$ and $\mathrm{O}_{3}$ were too low and were not considered for the exposure quantification. PM10 baseline concentrations were taken both outdoors and indoors in schools.

\section{TABLE 1 Description of the study population}

\begin{tabular}{|c|c|}
\hline Total subjects & $51(100)$ \\
\hline \multicolumn{2}{|l|}{ Sex } \\
\hline Males & $28(54.9)$ \\
\hline Females & $23(45.1)$ \\
\hline Age yrs & $7.3 \pm 1.1$ \\
\hline Height $\mathrm{cm}$ & $127.0(121.0-130.0)$ \\
\hline Weight kg & $27.5(25.0-32.0)$ \\
\hline BMI & $17.3(15.5-19.5)$ \\
\hline \multicolumn{2}{|l|}{ Parental education } \\
\hline Primary or secondary & $23(45.1)$ \\
\hline High school or university & $28(54.9)$ \\
\hline \multicolumn{2}{|l|}{ Atopy } \\
\hline No & $24(47)$ \\
\hline Yes & $27(53)$ \\
\hline \multicolumn{2}{|l|}{ Parental smoking } \\
\hline No & $41(80.4)$ \\
\hline Yes & $10(19.6)$ \\
\hline \multicolumn{2}{|l|}{ Older siblings } \\
\hline No & $22(43)$ \\
\hline Yes & $29(57)$ \\
\hline \multicolumn{2}{|c|}{ Mould or dampness at home } \\
\hline No & $45(88)$ \\
\hline Yes & $6(12)$ \\
\hline \multicolumn{2}{|l|}{ Pets at home } \\
\hline No & $31(61)$ \\
\hline Yes & $20(39)$ \\
\hline \multicolumn{2}{|l|}{ Fireplace at home } \\
\hline No & $23(45)$ \\
\hline Yes & $28(55)$ \\
\hline
\end{tabular}

Data are presented as $n(\%)$, mean \pm SD or median (interquartile range). BMI: body mass index. Age, height, weight and BMI concern the beginning of the study. 


\begin{tabular}{|c|c|c|c|c|}
\hline \multirow{2}{*}{$\begin{array}{l}\text { TABLE } 2 \\
\text { Pollutants }\end{array}$} & \multicolumn{4}{|c|}{$\begin{array}{l}\text { Concentrations of air pollutants for each visit } \\
\text { measured in houses and schools }\end{array}$} \\
\hline & Visit $1^{\#}$ & Visit $2^{\circ}$ & Visit $3^{\#}$ & Visit $4^{\circ}$ \\
\hline \multicolumn{5}{|l|}{ Houses $^{+}$} \\
\hline PM10 & $\mathrm{N} / \mathrm{M}$ & $\mathrm{N} / \mathrm{M}$ & $\mathrm{N} / \mathrm{M}$ & $\mathrm{N} / \mathrm{M}$ \\
\hline $\mathrm{NO}_{2}$ & Undetect & Undetect & Undetect & Undetect \\
\hline $\mathrm{O}_{3}$ & Undetect & Undetect & Undetect & Undetect \\
\hline Benzene & $\begin{array}{c}3.3 \\
(0.8-33.1)\end{array}$ & $\begin{array}{c}1.1 \\
(0.4-5.0)\end{array}$ & $\begin{array}{c}11.9 \\
(1.2-50.0)\end{array}$ & $\begin{array}{c}1.8 \\
(0.4-24.0)\end{array}$ \\
\hline Toluene & $\begin{array}{c}25.7 \\
(2.0-113.7)\end{array}$ & $\begin{array}{c}17.9 \\
(3.1-127.6)\end{array}$ & $\begin{array}{c}37.3 \\
(7.0-161.0)\end{array}$ & $\begin{array}{c}14.8 \\
(2.1-82.5)\end{array}$ \\
\hline Xylenes & $\begin{array}{c}13.3 \\
(1.4-182.6)\end{array}$ & $\begin{array}{c}7.9 \\
(2.0-37.3)\end{array}$ & $\begin{array}{c}9.8 \\
(1.1-271.0)\end{array}$ & $\begin{array}{c}10.4 \\
(1.1-113.0)\end{array}$ \\
\hline Ethylbenzene & $\begin{array}{c}3.5 \\
(0.4-55.0)\end{array}$ & $\begin{array}{c}2.0 \\
(0.7-7.3)\end{array}$ & $\begin{array}{c}22.8 \\
(5.2-83.0)\end{array}$ & $\begin{array}{c}2.4 \\
(0.6-22.0)\end{array}$ \\
\hline Formaldehyde & $\begin{array}{c}11.2 \\
(4.3-19.7)\end{array}$ & $\begin{array}{c}19.6 \\
(5.0-39.3)\end{array}$ & $\begin{array}{c}14.4 \\
(1.5-33.6)\end{array}$ & $\begin{array}{c}13.2 \\
(1.9-39.4)\end{array}$ \\
\hline \multicolumn{5}{|l|}{ Schools } \\
\hline PM10 & $\begin{array}{c}124.3 \\
(47.8-168.5)\end{array}$ & $\begin{array}{c}65.5 \\
(42.7-104.8)\end{array}$ & $\begin{array}{c}105.9 \\
(72.0-160.7)\end{array}$ & $\begin{array}{c}67.4 \\
(29.2-112.8)\end{array}$ \\
\hline $\mathrm{NO}_{2}$ & Undetect & Undetect & Undetect & Undetect \\
\hline $\mathrm{O}_{3}$ & Undetect & Undetect & Undetect & Undetect \\
\hline Benzene & $1.4(1.2-1.5)$ & $0.5(0.4-0.6)$ & $5.0(1.9-7.8)$ & $1.2(1.0-1.4)$ \\
\hline Toluene & $\begin{array}{c}38.0 \\
(4.3-78.7)\end{array}$ & $\begin{array}{c}10.7 \\
(3.4-27.6)\end{array}$ & $\begin{array}{c}22.4 \\
(12.0-31.0)\end{array}$ & $\begin{array}{c}11.6 \\
(3.6-26.0)\end{array}$ \\
\hline Xylenes & $\begin{array}{c}5.6 \\
(2.8-7.0)\end{array}$ & $\begin{array}{c}3.5 \\
(1.8-5.6)\end{array}$ & $\begin{array}{c}10.3 \\
(1.1-36.5)\end{array}$ & $\begin{array}{c}23.8 \\
(1.1-58.0)\end{array}$ \\
\hline Ethylbenzene & $\begin{array}{c}1.4 \\
(0.7-2.1)\end{array}$ & $\begin{array}{c}1.0 \\
(0.6-1.5)\end{array}$ & $\begin{array}{c}10.3 \\
(7.3-16.0)\end{array}$ & $\begin{array}{c}5.8 \\
(1.0-14.0)\end{array}$ \\
\hline Formaldehyde & $\begin{array}{c}11.2 \\
(4.3-19.7)\end{array}$ & $\begin{array}{c}10.0 \\
(5.4-20.0)\end{array}$ & $\begin{array}{c}7.5 \\
(5.0-12.4)\end{array}$ & $\begin{array}{c}2.2 \\
(1.1-3.3)\end{array}$ \\
\hline \multicolumn{5}{|l|}{ Outdoor } \\
\hline PM10 & $\begin{array}{c}40.5 \\
(17.4-92.7)\end{array}$ & $\begin{array}{c}41.7 \\
(26.8-53.0)\end{array}$ & $\begin{array}{c}66.4 \\
(32.3-133.9)\end{array}$ & $\begin{array}{c}36.6 \\
(30.9-41.8)\end{array}$ \\
\hline $\mathrm{NO}_{2}$ & $\begin{array}{c}21.0 \\
(15.0-28.0)\end{array}$ & $\begin{array}{c}12.0 \\
(7.0-18.0)\end{array}$ & $\begin{array}{c}17.0 \\
(6.0-25.0)\end{array}$ & $\begin{array}{c}12.0 \\
(9.0-16.0)\end{array}$ \\
\hline $\mathrm{O}_{3}$ & $\begin{array}{c}21.8 \\
(18.8-25.6)\end{array}$ & $\begin{array}{c}47.0 \\
(37.0-57.0)\end{array}$ & $\begin{array}{c}18.0 \\
(9.0-26.0)\end{array}$ & $\begin{array}{c}77.0 \\
(60.0-95.0)\end{array}$ \\
\hline Benzene & $1.3(0.9-1.6)$ & $0.7(0.5-1.1)$ & $3.5(2.2-5.0)$ & $1.2(0.9-1.4)$ \\
\hline Toluene & $2.3(1.4-3.2)$ & $2.9(1.8-4.3)$ & $6.0(4.2-8.6)$ & $2.4(2.0-2.9)$ \\
\hline Xylenes & $\begin{array}{c}2.1 \\
(1.6-2.5)\end{array}$ & $\begin{array}{c}2.3 \\
(1.1-4.2)\end{array}$ & $\begin{array}{c}1.9 \\
(1.1-4.2)\end{array}$ & $\begin{array}{c}1.2 \\
(1.1-1.3)\end{array}$ \\
\hline Ethylbenzene & $\begin{array}{c}0.4 \\
(0.3-0.6)\end{array}$ & $\begin{array}{c}0.6 \\
(0.3-1.1)\end{array}$ & $\begin{array}{c}5.0 \\
(1.0-8.8)\end{array}$ & $\begin{array}{c}1.0 \\
(1.0-1.0)\end{array}$ \\
\hline Formaldehyde & $\begin{array}{c}2.3 \\
(2.1-2.8)\end{array}$ & $\begin{array}{c}2.3 \\
(1.7-2.6)\end{array}$ & $\begin{array}{c}3.6 \\
(3.0-4.3)\end{array}$ & $\begin{array}{c}0.7 \\
(0.2-1.4)\end{array}$ \\
\hline
\end{tabular}

Data are presented in $\mu \mathrm{g} \cdot \mathrm{m}^{-3}$ as mean concentrations among the $\mathrm{n}$ schools/ houses (minimum of the concentrations of the $\mathrm{n}$ schools/houses-maximum of the concentrations of the $n$ schools/houses). PM10: particles with a $50 \%$ cut-off aerodynamic diameter of $10 \mu \mathrm{m} ; \mathrm{N} / \mathrm{M}$ : not measured; Undetect: undetectable measurement. ${ }^{\#}$ : visits in January; ": visits in June; ${ }^{+}$: indoor pollutants.

PM10 concentrations were high inside the schools. Both houses and schools constituted an important source of VOCs. VOC concentrations were higher in indoor environments (with the exception of benzene) than outdoors. There was a different pattern across the visits, with $\mathrm{PM} 10$ and $\mathrm{NO}_{2}$ reaching higher concentrations in January than in June, whereas for $\mathrm{O}_{3}$ the opposite was true.

Quantifications of children's total exposure to the different pollutants are presented in table 3. Children had similar daily activity patterns with the majority of the exposure time spent in indoor environments, namely their homes (65\%) and schools (20\%). Regarding the seasonal variability, time spent indoors in winter was slightly higher than in summer, without reaching statistical significance $(p=0.283)$. Children spent $>22 \mathrm{~h}$ in indoor environments each day, despite the time of the year. The only difference was that in summer, children spent a little more time in the courtyard of the school and outside their homes (on average $<30$ min more). Considering the child's exposure, air pollutants were correlated with each other at each visit (see online supplement). Statistically significant positive correlations existed among various air pollutants, namely for VOCs such as tolueneethylbenzene, toluene-xylene, xylene-ethylbenzene and benzeneethylbenzene. $\mathrm{NO}_{2}$ and ozone also presented a trend to be positively correlated. Conversely, PM10 and $\mathrm{NO}_{2}$, and PM10 and $\mathrm{O}_{3}$ were inversely correlated.

The results of spirometry, inflammation assessment and clinical outcomes across the studied seasons are presented in table 4. Most children did not present abnormal changes during the study period but, in each evaluation, $\sim 25 \%$ presented a $\triangle \mathrm{FEV} 1$ $>12 \%$. There were differences in spirometric changes (FEV1: $p=0.010$; FEV1/FVC: $p=0.092$ ) between the four evaluations, but more significant differences were found for the inflammation parameters $(\mathrm{p}<0.001)$. This is in accordance with the known agerelated changes in FeNO [23] and for the predicted spirometric values [24] that can spuriously introduce a trend of lung function deterioration without clinical significance.

According to GEE (table 5, figs 1 and 2), after adjustment, increasing individual exposure to PM10 in the studied week was associated with a trend of airway deterioration, reaching significance with a decrease of the FEV1 (regression coefficient $-1.64,95 \%$ CI $-3.20--0.10)$ and $\mathrm{pH}$ on EBC (-0.21, 95\% CI -0.30- -0.12) and an increase of $\triangle \mathrm{FEV} 1(1.19,95 \% \mathrm{CI} 0.12-2.26)$. Associations were also found for an increase of $\mathrm{NO}_{2}$ exposure: decrease of FEV1 (-6.31, 95\% CI -11.87- -0.76), FEV1/FVC (-2.79, 95\% CI -5.71-0.14), FEF25-75\% (-10.20, 95\% CI -18.80- -1.59) and pH on EBC (-0.69, $95 \%$ CI $-1.04--0.35)$, and an increase of $\triangle \mathrm{FEV} 1$ (4.72, 95\% CI $0.91-$ 8.53). No associations were found for $\mathrm{O}_{3}$ after adjustment.

Benzene, toluene and ethylbenzene were the VOC for which we found a significant association between increasing exposure and airway changes (table 5 and fig. 1), with all three being related to a deterioration of lung function. For benzene, we found a decrease of FEV1 (regression coefficients -4.33, 95\% CI -7.13- -1.53), FEV1/ FVC $(-1.71,95 \%$ CI $-3.24--0.18)$ and FEF $25-75 \%(-5.89,95 \%$ CI $-10.16-1.62)$ and an increase of $\triangle \mathrm{FEV} 1(2.79,95 \%$ CI $0.92-4.65)$. For toluene, we found a decrease of FEV1 (-1.10, 95\% CI -1.97- -0.23) and an increase of $\triangle \mathrm{FEV} 1(0.97,95 \%$ CI $0.44-1.50)$. For ethylbenzene we observed a decrease of FEV1 $(-1.79,95 \%$ CI $-3.32--0.25)$ and FEF25-75\% $(-2.48,95 \%$ CI $-4.81--0.16)$ and an increase of $\triangle \mathrm{FEV} 1(1.30,95 \% \mathrm{CI} 0.27-2.35)$.

For VOCs, EBC pH exhibited a consistent trend of negative associations (fig. 2), reaching significance in the case of benzene 
TABLE 3 Quantification of total children's exposure to air pollutants and weather conditions in the children seen at each visit

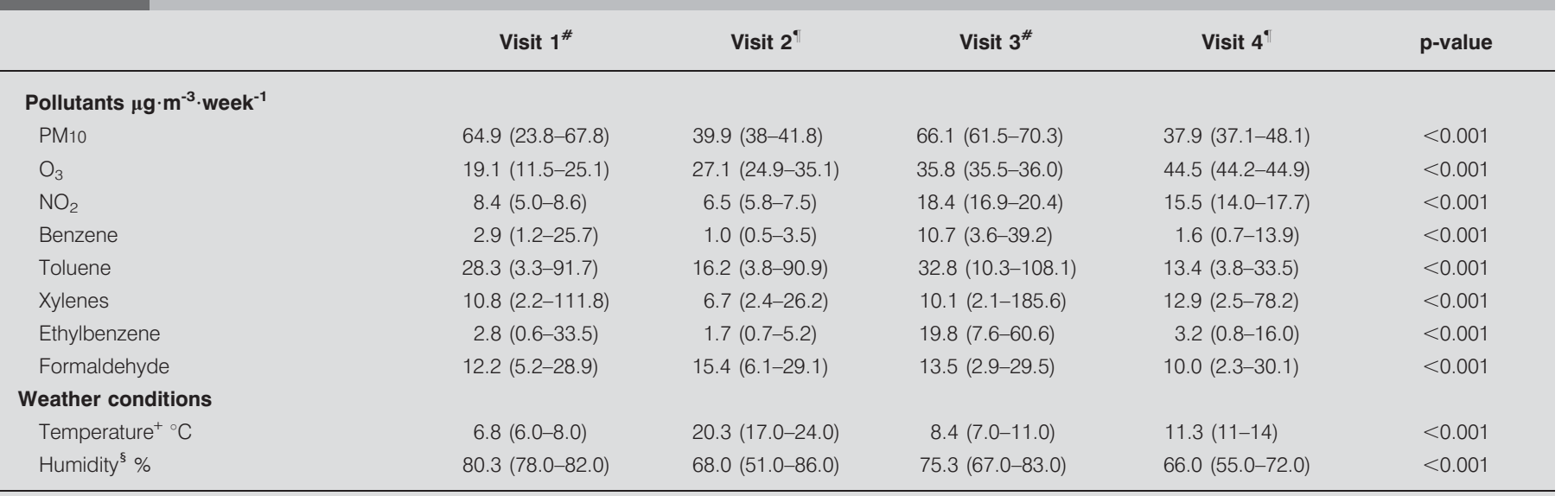

Data are presented as mean (minimum-maximum) for each visit, unless otherwise stated. PM10: particles with a $50 \%$ cut-off aerodynamic diameter of $10 \mu \mathrm{m}$. ${ }^{\#}$ : visits in January; ${ }^{\prime}$ : visits in June; ${ }^{+}$: average temperature on the day of the visit; ${ }^{\S}$ : relative humidity on the day of the visit. Total exposure for the child in the studied week was calculated using the following equation:

$\operatorname{Exp}_{i}=\sum_{j=1}^{n} C_{j} t_{i, j}$

where $\operatorname{Exp}_{i}$ is the total exposure for the child $i$ over the specified period of time; $C_{j}$ is the pollutant concentration in each microenvironment $j$ and $t_{i, j}$ is the time spent by the person $i$ in microenvironment $j$.

$(-0.24,95 \%$ CI $-0.42--0.06)$ and ethylbenzene $(-0.14,95 \%$ CI $-0.23--0.04)$. VOCs also presented a trend of positive associations with FeNO, namely ethylbenzene (1.99, 95\% CI -0.00-3.99).

Clinical outcomes were positively associated with toluene, for which an increase of rescue medication and emergency department visits were related with increasing exposure: 0.21 (95\% CI $0.01-0.42$ ) and 0.26 (95\% CI $0.06-0.46)$, respectively (table 6). Positive associations were also found between need of rescue medication and benzene $(0.76,95 \%$ CI $-0.11-1.62)$ and ethylbenzene $(0.45,95 \%$ CI $0.02-0.87)$. The negative associations between increasing exposure to PM10 $(-0.70,95 \% \mathrm{CI}-1.14--0.25)$ and $\mathrm{NO}_{2}$ $(-2.08,95 \%$ CI $-3.59--0.58)$ and a decrease of reported wheezing symptoms were unexpected.
The results from the application of two-pollutant models for FEV1 and $\mathrm{pH}$ on $\mathrm{EBC}$ are presented in the online supplement. Results that were similar, although not significant, to those of the onepollution model were observed in the case of FEV1; benzene was the only pollutant that persisted with statistically significant negative associations but for $\mathrm{pH}, \mathrm{PM} 10$ was the pollutant that prevailed.

\section{DISCUSSION}

In this study, we methodically assessed total exposure of children to different pollutants. To this extent, we took into account the different indoor and outdoor environments where children spend their day, which can provide different concentrations of

TABLE 4 Spirometry, airway inflammation parameters and clinical outcomes in the children seen at each visit

\begin{tabular}{|c|c|c|c|c|c|}
\hline & Visit $1^{\#}$ & Visit $2^{\circ}$ & Visit $3^{\#}$ & Visit $4^{\circ}$ & $p$-value \\
\hline \multicolumn{6}{|l|}{ Spirometry } \\
\hline FEV $1 / F V C$ & $0.78(0.73-0.84)$ & $0.80(0.75-0.85)$ & $0.79(0.74-0.83)$ & $0.80(0.76-0.84)$ & 0.092 \\
\hline FEF $25-75 \%$ & $79.5(61-105)$ & $83(63-108)$ & 76 (63-95) & $77(64-101)$ & $>0.100$ \\
\hline$\Delta \mathrm{FEV}_{1} \%$ & $7(3-14.5)$ & $6(3-13)$ & $7.5(5-13)$ & $7(3-11)$ & $>0.100$ \\
\hline $\mathrm{pH}$ EBC & $8.41(8.23-8.50)$ & $8.06(7.71-8.26)$ & $7.76(7.05-8.11)$ & $8.07(7.48-8.27)$ & 0.001 \\
\hline \multicolumn{6}{|l|}{ Clinical outcomes $^{+}$} \\
\hline Wheezing & $46(90)$ & $27(53)$ & $22(43.1)$ & 20 (39.2) & 0.001 \\
\hline Rescue medication & $27(53)$ & $19(37.7)$ & $19(37.7)$ & 18 (35.3) & 0.068 \\
\hline Emergency department & $16(31.3)$ & $9(17)$ & $6(11.8)$ & $4(7.8)$ & 0.006 \\
\hline
\end{tabular}

Data are presented as median (interquartile range) or $\mathrm{n}(\%)$, unless otherwise stated. FEV1: forced expiratory volume in 1 s; FVC: forced vital capacity; FEF25-75\%: forced expiratory flow between $25-75 \%$ of $\mathrm{FVC} ; \triangle \mathrm{FEV} 1$ : increase of $\mathrm{FEV} 1$ as a percentage of the initial value after bronchodilator; FeNO: exhaled nitric oxide fraction; EBC: exhaled breath condensate. ${ }^{\#}$ : visits in January; ${ }^{?}$ : visits in June; ${ }^{+}$: clinical outcomes concern the previous 6 months. 
TABLE 5 Relationships between children's total exposure to air pollutants and spirometric and inflammatory parameters

\begin{tabular}{|c|c|c|c|c|c|c|}
\hline PM10 & $\begin{array}{c}-1.64(-3.20--0.10) \\
p=0.037\end{array}$ & $\begin{array}{c}-0.56(-1.37-0.26) \\
\text { NS }\end{array}$ & $\begin{array}{c}-1.55(-3.97-0.96) \\
\text { NS }\end{array}$ & $\begin{array}{c}1.19(0.12-2.26) \\
p=0.030\end{array}$ & $\begin{array}{c}-0.21(-0.30--0.12) \\
p<0.001\end{array}$ & $\begin{array}{c}1.02(-0.93-2.97) \\
\text { NS }\end{array}$ \\
\hline $\mathrm{O}_{3}$ & $\begin{array}{c}-3.83(-13.16-5.49) \\
\text { NS }\end{array}$ & $\begin{array}{c}-0.03(-4.89-4.84) \\
\text { NS }\end{array}$ & $\begin{array}{c}-5.45(-19.95-9.04) \\
\text { NS }\end{array}$ & $\begin{array}{c}2.19(-3.81-8.19) \\
\text { NS }\end{array}$ & $\begin{array}{c}0.17(-0.40-0.74) \\
\text { NS }\end{array}$ & $\begin{array}{c}-5.06(-16.24-6.12) \\
\text { NS }\end{array}$ \\
\hline $\mathrm{NO}_{2}$ & $\begin{array}{c}-6.31(-11.87--0.76) ; \\
p=0.026\end{array}$ & $\begin{array}{c}-2.79(-5.71-0.14) \\
p=0.062\end{array}$ & $\begin{array}{c}-10.20(-18.80--1.59) \\
p=0.020\end{array}$ & $\begin{array}{c}4.72(0.91-8.53) \\
p=0.015\end{array}$ & $\begin{array}{c}-0.69(-1.04--0.35) \\
p<0.001\end{array}$ & $\begin{array}{c}3.72(-3.26-10.71) \\
\text { NS }\end{array}$ \\
\hline Toluene & $\begin{array}{c}-1.10(-1.97--0.23) \\
p=0.013\end{array}$ & $\begin{array}{c}-0.23(-0.70-0.25) \\
\text { NS }\end{array}$ & $\begin{array}{c}-1.14(-2.49-0.21) \\
p=0.098\end{array}$ & $\begin{array}{c}0.97(0.44-1.50) \\
p<0.001\end{array}$ & $\begin{array}{c}-0.03(-0.08-0.03) \\
\text { NS }\end{array}$ & $\begin{array}{c}0.94(-0.15-2.03) \\
\quad p=0.090\end{array}$ \\
\hline Xylenes & $\begin{array}{c}-0.25(-1.07-0.56) \\
\text { NS }\end{array}$ & $\begin{array}{c}0.09(-0.35-0.54) \\
\text { NS }\end{array}$ & $\begin{array}{c}-0.22(-1.47-1.02) \\
\text { NS }\end{array}$ & $\begin{array}{c}-0.29(-0.83-0.25) \\
\text { NS }\end{array}$ & $\begin{array}{c}-0.00(-0.05-0.06) \\
\text { NS }\end{array}$ & $\begin{array}{c}0.61(-0.45-1.67) \\
\text { NS }\end{array}$ \\
\hline
\end{tabular}

Data are presented as regression coefficient $(95 \% \mathrm{Cl})$; p-value. Regression coefficients were adjusted for time of the evaluation, sex, age, atopy, height, weight, older siblings, parental education, parental smoking, average temperature, relative humidity, pets at home, fireplace at home, and mould or dampness at home. Regression coefficients $(95 \% \mathrm{Cl})$ represent the mean change in spirometric and inflammatory parameters for increments of $10 \mu \mathrm{g} \cdot \mathrm{m}^{-3} \cdot$ week $^{-1}$ of air pollutant. FEV1: forced expiratory volume in $1 \mathrm{~s}$; FVC: forced vital capacity; FEF25-75\%: forced expiratory flow between 25-75\% of FVC; $\triangle F E V 1$ : increase of FEV1 as a percentage of the initial value after bronchodilator; EBC: exhaled breath condensate; FeNO: exhaled nitric oxide fraction; PM10: particles with a $50 \%$ cut-off aerodynamic diameter of $10 \mu \mathrm{m}$; NS: nonsignificant, p-value $>0.100$

pollutants. Our data illustrate that mean levels of major air pollutants in just one microenvironment could either underestimate or overestimate the real exposure of the child. Differences in air quality were found between houses and schools. Moreover, there were also differences between houses.

During the week of the study, increasing total exposure to PM10, $\mathrm{NO}_{2}$, benzene, toluene and ethylbenzene was associated with a decrease of FEV1 and an increase of $\triangle \mathrm{FEV} 1$. Increased exposure to $\mathrm{NO}_{2}$ and benzene was also associated with a decrease of FEV1/ FVC and FEF25-75\% while ethylbenzene was also associated with a decrease of $\mathrm{FEF} 25-75 \%$. Increasing exposure to $\mathrm{PM} 10, \mathrm{NO}_{2}$, benzene and ethylbenzene was associated with acidity of EBC.

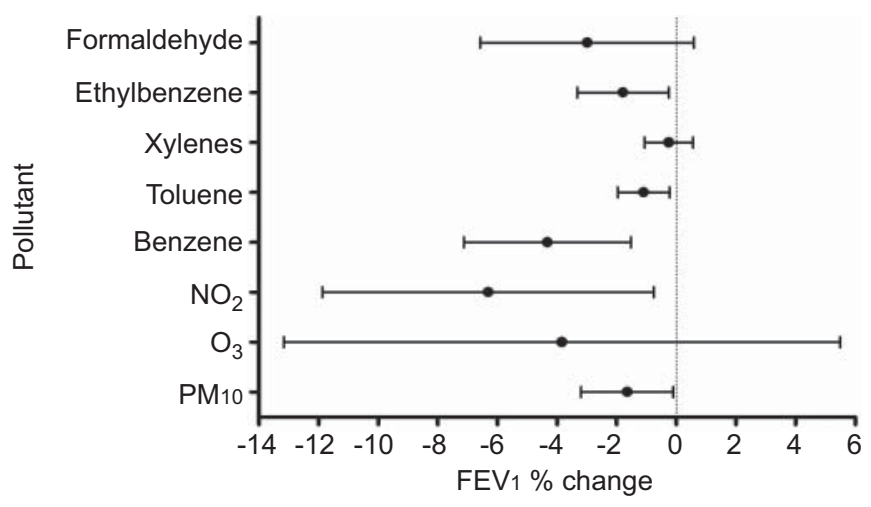

FIGURE 1. Per cent changes and corresponding $95 \%$ confidence intervals (whiskers) in forced expiratory volume in $1 \mathrm{~s}(\mathrm{FEV} 1)$ for $10-\mu \mathrm{g} \cdot \mathrm{m}^{-3} \cdot \mathrm{week}^{-1}$ increments of air pollutant, after adjustment. PM10: particles with a $50 \%$ cut-off aerodynamic diameter of $10 \mu \mathrm{m}$.
Ethylbenzene was the only pollutant with a significant positive association with $F$ eNO. Toluene was the only pollutant positively associated with symptoms in the previous months.

Exposure to PM10, as estimated using a function of both concentrations and daily activity patterns, was related to lung function decline, even in a non-industrial city. We did not find any significant association between PM10 and FeNO as suggested in other studies $[9,25]$, although we adjusted the analysis for important confounding factors [23]. However, it should be noted that in our study, airway acidity was related to different pollutants, namely $\mathrm{PM} 10, \mathrm{NO}_{2}$, benzene and ethylbenzene, suggesting a link between airways inflammation.

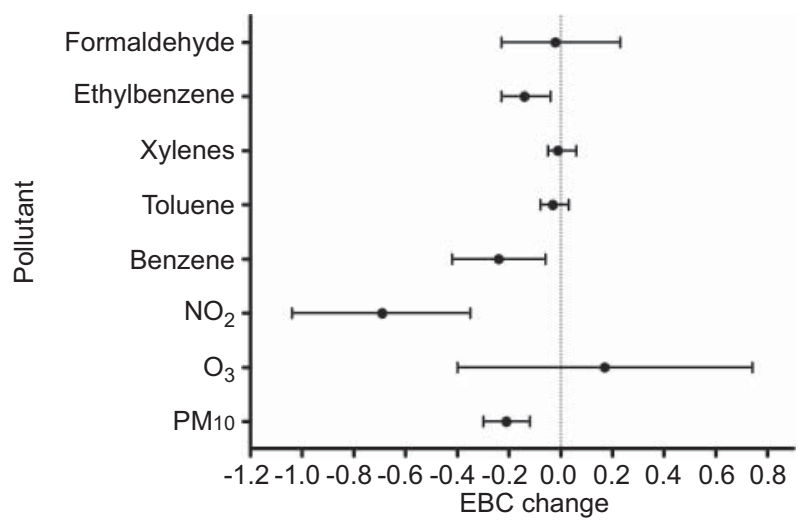

FIGURE 2. Exhaled breath condensate (EBC) $\mathrm{pH}$ changes and $95 \%$ confidence intervals (whiskers) for $10-\mu \mathrm{g} \cdot \mathrm{m}^{-3} \cdot$ week $^{-1}$ increments of air pollutant, after adjustment. PM10: particles with a $50 \%$ cut-off aerodynamic diameter of $10 \mu \mathrm{m}$. 


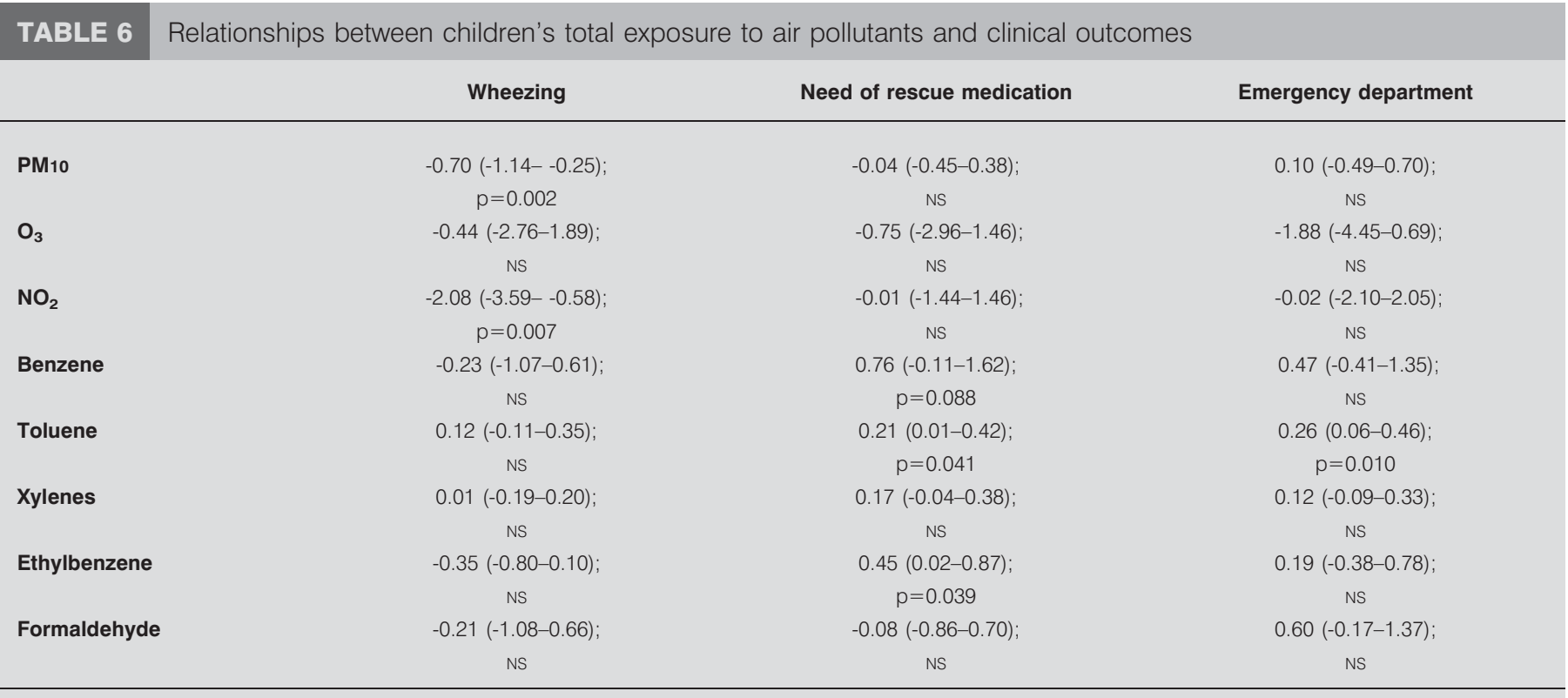

Data are presented as regression coefficient $(95 \% \mathrm{Cl}) ; \mathrm{p}$-value. Regression coefficients were adjusted for time of the evaluation, sex, age, atopy, height, weight, older siblings, parental education, parental smoking, average temperature, relative humidity, pets at home, fireplace at home, and mould or dampness at home. Regression coefficients $\left(95 \% \mathrm{Cl}\right.$ ) represent the mean change in clinical outcomes for increments of $10 \mu \mathrm{g} \cdot \mathrm{m}^{-3} \cdot \mathrm{week}^{-1}$ of air pollutant. PM10: particles with a $50 \%$ cut-off aerodynamic diameter of $10 \mu \mathrm{m}$; Ns: nonsignificant, $\mathrm{p}$-value $>0.100$.

The spirometric findings for $\mathrm{PM} 10$ and $\mathrm{NO}_{2}$ are not in agreement with the negative associations found for wheezing in the previous months. This could to be in accordance with a previous study [26] where increasing exposure to PM10 was associated with reduction in peak expiratory flow, but not with wheezing or dyspnoea.

Benzene, toluene and ethylbenzene were the VOCs associated with lung function deterioration and airway inflammation. Toluene is a known cause of occupational asthma [27], where exposure to higher levels is common. Low levels of VOCs seem to increase the risk of childhood [19] and adult [28] asthma symptoms but associations with lung function have been more difficult to find [29]. Ethylbenzene has also been suggested as a significant risk factor for asthma [19], a fact that is in accordance with the airways changes found in our study.

To our knowledge, this is the first time that associations between individual's exposure to air pollution, using both indoor and outdoor air pollution monitoring and modelling techniques, and various respiratory outcomes were observed simultaneously. Our final results are in agreement with most previous epidemiological evidence on either outdoor or indoor measurements. Other panel studies with asthmatic children looked for associations between air pollutants and airways changes through a comprehensive assessment that included spirometry, FeNO and EBC analysis [9, 30]. However, in the majority of previous studies, only outdoor air pollutants were taken into account. In a panel study with 53 asthmatic children, DeLFINO et al. [21] assessed PM2.5 and $\mathrm{NO}_{2}$ through personal active air samplers worn in a backpack, reaching a negative association between FEV1 and increasing personal exposure to $\mathrm{PM} 2.5$ and $\mathrm{NO}_{2}$.

A major strength of our study is the fact that for each child, the exposure calculation took into account different indoor (home and school) and outdoor microenvironments through direct measurements or modelling methods, combining daytime activities. It has recently been indicated that future research will require increasing specificity of exposure assessment to identify the potential roles of individual exposure to air pollution components. This could elucidate potential mechanisms and facilitate studies of mixtures and gene-air pollution interactions [31]. It could be important, namely for PM10, $\mathrm{NO}_{2}$ and benzene, as they usually have urban transport as their major sources. However, in our study, traffic exhaust did not seem to be the most important source of PM10 and benzene for individual exposure. In addition, the correlation matrix among the pollutants showed that the patterns were strongly influenced by the daytime activity profile and by the different environments used for the exposure calculation, which is difficult to take into account.

Additionally, we chose a prospective study with repeated measures and with uniform medical evaluations and exposure assessments to different pollutants. The use of different objective outcomes (spirometric and inflammatory) is also a point that we should emphasise.

A limitation of our investigation could result from the fact that we considered only 4 weeks of a child's life which prevents the study of causality. We did not consider the weekends and we are aware that this approach may have affected the total exposure to important indoor residential air pollutants. Furthermore, the proper role of each pollutant could not be identified in our study. However, new data have shown that multi-pollution is an important phenomenon to take into account in the assessment of health effects of air quality [32]. In order to deal with this issue, we applied two-pollutant models. However, this approach does not allow us to fully take into account the effects of the other pollutants. Therefore, our data do not allow the separate effects of the various pollutants to be established but the observed effects 
can be indicative of a pollution mix. In addition, we decided to study only the effects of individual exposure to air pollutants over the airways in a susceptible group: wheezers. A future research area to clarify the links between air pollution and respiratory effects should include a control group.

\section{Conclusion}

Our study suggests a relationship between total exposure to air pollutants assessed in various environments and airways changes in wheezing children. It also suggests that attention should be dedicated to air quality in houses and schools in childhood as the majority of the children's time is spent in these environments, and namely to VOCs. These pollutants that are very common nowadays seem to have an impact on airways even at low concentrations [33].

\section{ACKNOWLEDGEMENTS}

The authors would like to thank the children and their parents. We thank also the school teachers and the authorities of Viseu, Portugal, who welcomed the study.

\section{SUPPORT STATEMENT}

The Saud'Ar study was supported by Fundação Calouste Gulbenkian. The authors thank the Portuguese Foundation for Science and Technology for the PhD grant of J. Valente (SFRH/BD/22687/2005).

\section{STATEMENT OF INTEREST}

None declared.

\section{REFERENCES}

1 Hwang BF, Lee YL, Lin YC, et al. Traffic related air pollution as a determinant of asthma among Taiwanese school children. Thorax 2005; 60: 467-473.

2 Penard-Morand C, Charpin D, Raherison C, et al. Long-term exposure to background air pollution related to respiratory and allergic health in schoolchildren. Clin Exp Allergy 2005; 35: 1279-1287.

3 Penard-Morand C, Raherison C, Charpin D, et al. Long-term exposure to proximity air pollution and asthma and allergies in urban children. Eur Respir J 2010; 36: 33-40.

4 McConnell R, Berhane K, Gilliland F, et al. Prospective study of air pollution and bronchitic symptoms in children with asthma. Am J Respir Crit Care Med 2003; 168: 790-797.

5 Epton MJ, Dawson RD, Brooks WM, et al. The effect of ambient air pollution on respiratory health of school children: a panel study. Environ Health 2008; 7: 16.

6 Dales R, Chen L, Frescura AM, et al. Acute effects of outdoor air pollution on forced expiratory volume in $1 \mathrm{~s}$ : a panel study of schoolchildren with asthma. Eur Respir J 2009; 34: 316-323.

7 Escamilla-Nunez MC, Barraza-Villarreal A, Hernandez-Cadena L, et al. Traffic-related air pollution and respiratory symptoms among asthmatic children, resident in Mexico City: the EVA cohort study. Respir Res 2008; 9: 74.

8 Delfino RJ, Quintana PJ, Floro J, et al. Association of FEV1 in asthmatic children with personal and microenvironmental exposure to airborne particulate matter. Environ Health Perspect 2004; 112: 932-941.

9 Liu L, Poon R, Chen L, et al. Acute effects of air pollution on pulmonary function, airway inflammation, and oxidative stress in asthmatic children. Environ Health Perspect 2009; 117: 668-674.

10 Gauderman WJ, Vora H, McConnell R, et al. Effect of exposure to traffic on lung development from 10 to 18 years of age: a cohort study. Lancet 2007; 369: 571-577.

11 Flamant-Hulin M, Caillaud D, Sacco P, et al. Air pollution and increased levels of fractional exhaled nitric oxide in children with no history of airway damage. J Toxicol Environ Health A 2010; 73 272-283.

12 McConnell R, Berhane K, Gilliland F, et al. Air pollution and bronchitic symptoms in Southern California children with asthma. Environ Health Perspect 1999; 107: 757-760.

13 Sahsuvaroglu T, Jerrett M, Sears MR, et al. Spatial analysis of air pollution and childhood asthma in Hamilton, Canada: comparing exposure methods in sensitive subgroups. Environ Health 2009; 8: 14

14 Wilkinson P, Elliott P, Grundy C, et al. Case-control study of hospital admission with asthma in children aged 5-14 years: relation with road traffic in north west London. Thorax 1999; 54: 1070-1074.

15 Sousa SI, Alvim-Ferraz MC, Martins FG, et al. Ozone exposure and its influence on the worsening of childhood asthma. Allergy 2009; 64: 1046-1055.

16 Simoni M, Annesi-Maesano I, Sigsgaard T, et al. School air quality related to dry cough, rhinitis and nasal patency in children. Eur Respir J 2010; 35: 742-749.

17 Holt PG, Macaubas C, Stumbles PA, et al. The role of allergy in the development of asthma. Nature 1999; 402: B12-B17.

18 McCormack MC, Breysse PN, Matsui EC, et al. In-home particle concentrations and childhood asthma morbidity. Environ Health Perspect 2009; 117: 294-298.

19 Rumchev K, Spickett J, Bulsara M, et al. Association of domestic exposure to volatile organic compounds with asthma in young children. Thorax 2004; 59: 746-751.

20 Tang CS, Chang LT, Lee HC, et al. Effects of personal particulate matter on peak expiratory flow rate of asthmatic children. Sci Total Environ 2007; 382: 43-51.

21 Delfino RJ, Staimer N, Tjoa $\mathrm{T}$, et al. Personal and ambient air pollution exposures and lung function decrements in children with asthma. Environ Health Perspect 2008; 116: 550-558.

22 Gerharz LE, Kruger A, Klemm O. Applying indoor and outdoor modeling techniques to estimate individual exposure to PM2.5 from personal GPS profiles and diaries: a pilot study. Sci Total Environ 2009; 407: 5184-5193.

23 Olin AC, Rosengren A, Thelle DS, et al. Height, age, and atopy are associated with fraction of exhaled nitric oxide in a large adult general population sample. Chest 2006; 130: 1319-1325.

24 Quanjer PH, Borsboom GJ, Brunekreef B, et al. Spirometric reference values for white European children and adolescents: Polgar revisited. Pediatr Pulmonol 1995; 19: 135-142.

25 Delfino RJ, Staimer N, Gillen D, et al. Personal and ambient air pollution is associated with increased exhaled nitric oxide in children with asthma. Environ Health Perspect 2006; 114: 1736-1743.

26 Vedal S, Petkau J, White R, et al. Acute effects of ambient inhalable particles in asthmatic and nonasthmatic children. Am J Respir Crit Care Med 1998; 157: 1034-1043.

27 Ott MG, Diller WF, Jolly AT. Respiratory effects of toluene diisocyanate in the workplace: a discussion of exposure-response relationships. Crit Rev Toxicol 2003; 33: 1-59.

28 Arif AA, Shah SM. Association between personal exposure to volatile organic compounds and asthma among US adult population. Int Arch Occup Environ Health 2007; 80: 711-719.

29 Nielsen GD, Larsen ST, Olsen O, et al. Do indoor chemicals promote development of airway allergy? Indoor Air 2007; 17: 236-255.

30 Barraza-Villarreal A, Sunyer J, Hernandez-Cadena L, et al. Air pollution, airway inflammation, and lung function in a cohort study of Mexico City schoolchildren. Environ Health Perspect 2008; 116: 832-838.

31 Brauer M. How much, how long, what, and where: air pollution exposure assessment for epidemiologic studies of respiratory disease. Proc Am Thorac Soc 2010; 7: 111-115.

32 Billionnet C, Gay E, Kirchner S, et al. Quantitative assessments of indoor air pollution and respiratory health in a population-based sample of French dwellings. Environ Res 2011; 111: 425-434.

33 Hulin M, Caillaud D, Annesi-Maesano I. Indoor air pollution and childhood asthma: variations between urban and rural areas. Indoor Air 2010; 20: 502-514. 